\title{
Evaluación Heurística de las sedes web de los medios digitales: El País y El Mundo
}

\author{
Matilde Roa Amaya
}

Jorge Caldera Serrano

Recibido: 1.12.2011

Aceptado: 12.12.2011

\section{Resumen}

Se realiza la evaluación heurística atendiendo a los parámetros confeccionados por Hassan y Martín de los principales periódicos digitales de nuestro país: El Mundo y El País. Se estiman los más relevantes al ser los que cuentan con mayor venta de ejemplares en su tirada en papel, contando por tanto con mayor número de lectores y mayor difusión.

\section{Palabras clave}

Evaluación Heurística, sedes Web, Periódico El Mundo, Periódico El País

\section{Abstract}

Heuristic evaluation is performed taking into account the parameters made by Hassan and Martin of the major online newspapers in our country: El Mundo and El Pais. Are estimated to be more relevant to those with higher sales of copies in circulation paper, accounting for much more readership and more widespread.

\section{Key Words}

Heuristic Evaluation, Web sites, El Mundo Newspaper, El País newspaper

\section{INTRODUCCIÓN Y JUSTIFICACIÓN}

La Sociedad de la Información ha hecho necesario un cambio de paradigma en las formas de hacer y entender en prácticamente todos los ámbitos de la vida, tanto es así que ha habido un cambio de modelo productivo, social e incluso global. Las comunicaciones han cambiado, los mecanismos por los cuales se intercambia información y conocimiento se han generalizado y globalizado, los "nativos digitales" han fagotizado a las generaciones anteriores, han asimilado nuevas formas de hacer $y$ entender de manera innata, sin necesidad de complejas adaptaciones mentales, como sí hemos tenido que sufrir los "inmigrantes digitales".

Es en este panorama donde los medios de comunicación observan la necesidad de cambiar de modelo de negocio. La Red ya no es sólo una forma de entretenimiento sino de acceso a la información, y para muchos, la única forma de acceso a la información.

Esto hace que todos los medios -al menos los más importantes- cuenten con su "alter ego" en Internet, facilitando información a sus potenciales clientes tiempo real. 
Parecía interesante el realizar un trabajo en el cual se analizasen, desde un punto de vista heurístico, las web de estos medios digitales, para así determinar la valía de los mismos.

\section{MEDIOS DIGITALES ANALIZADOS: EL PAÍS Y EL MUNDO}

El objetivo del presente trabajo consiste en analizar las sedes web de periódicos digitales generalistas nacionales de España, validando por tanto la evaluación heurística para estos medios. El criterio de selección de los distintos periódicos ha sido tanto el número de lectores, según datos del Estudio General de Medios (EGM) como el Promedio de Difusión según datos de la Oficina de Justificación de la Difusión (OJD) en el último año.

A tener de lo expuesto, y teniendo presente que los resultados no pretenden mostrar una validez estadística sino el análisis de los principales medios nacionales, se ha decidido el análisis de dos medios de tirada nacional. No obstante, debe quedar claro que las nuevas tecnologías y la distribución por la red han cambiado radicalmente el criterio de tirada nacional y regional, siendo potencialmente en la actualidad, una difusión global.

Los periódicos analizados por tanto son:

\begin{tabular}{lll}
\hline Diarios & Número de lectores & Difusión \\
\hline El País & 1.997 .000 & 370.080 \\
El Mundo & 1.245 .000 & 284.901 \\
\hline
\end{tabular}

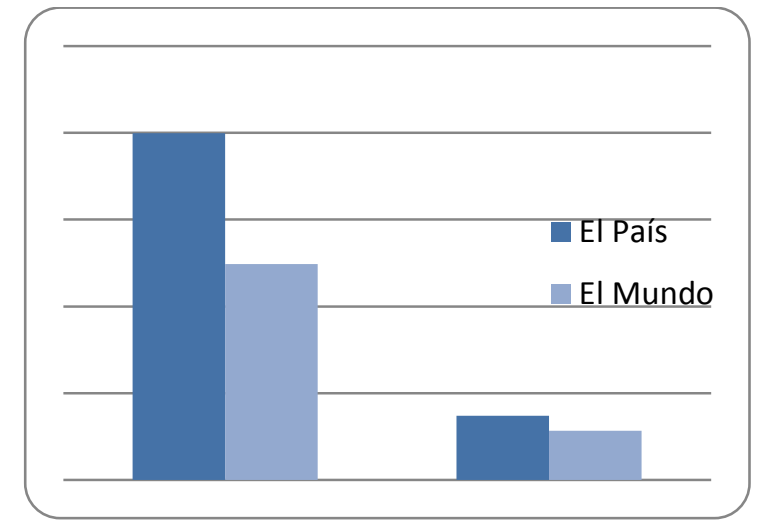

Figura 1. Difusión y lectores: El país y El Mundo.

\section{ELEMENTOS DESCRITOS DE LAS SEDES WEB DE LOS MEDIOS}

Se ha tomado como referencia La Guía de Evaluación Heurística de Sitios Web de Yusef Hassan Montero y Francisco Jesús Martín Fernández.

Se trata de un documento dividido en diferentes aspectos a analizar y formado cada uno de ellos por distintas cuestiones a las que responder de manera afirmativa indicamos que no existe problema alguno de usabilidad y la respuesta negativa indicaría lo contrario.

Los aspectos en los que se divide este apartado son: 
- Generales

- Identidad e Información

- Lenguaje y Redacción

- Rotulado, Estructura y Navegación

- Lay-out de la página

- Búsqueda

- Elementos multimedia

- Accesibilidad

\section{EL PAÍS DIGITAL}

\section{EL PAÍS.COM}

La edición impresa del diario El País aparece en el año 1976 y su fundador es José Ortega Spottorno. Perteneciente al grupo de comunicación Prisa, se ha convertido en el diario que cuenta con un mayor número de lectores, tanto en su edición impresa como en su edición digital. Su director actual es Javier Moreno y su editor responsable es Grupo Prisa.

Cuenta con un total de 2 ediciones: Edición Global y Edición Nacional.

A) Información general

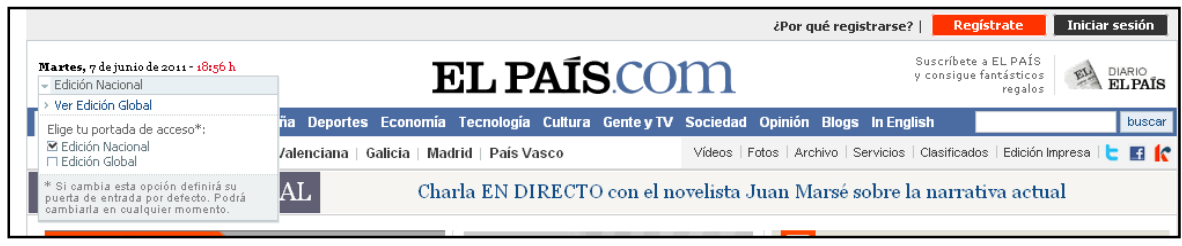

Objetivos

El sitio web del diario El País no contiene de forma explícita cuáles son sus objetivos. En cambio, la forma para conocerlos es enlazar con la página web del grupo de comunicación al que pertenece, Prisa, que tiene un espacio dedicado a cada uno de sus medios en el que se ofrece una breve descripción de lo que cada uno es.

URL 
La edición electrónica del diario El País se encuentra en la siguiente URL: www.elpais.com.

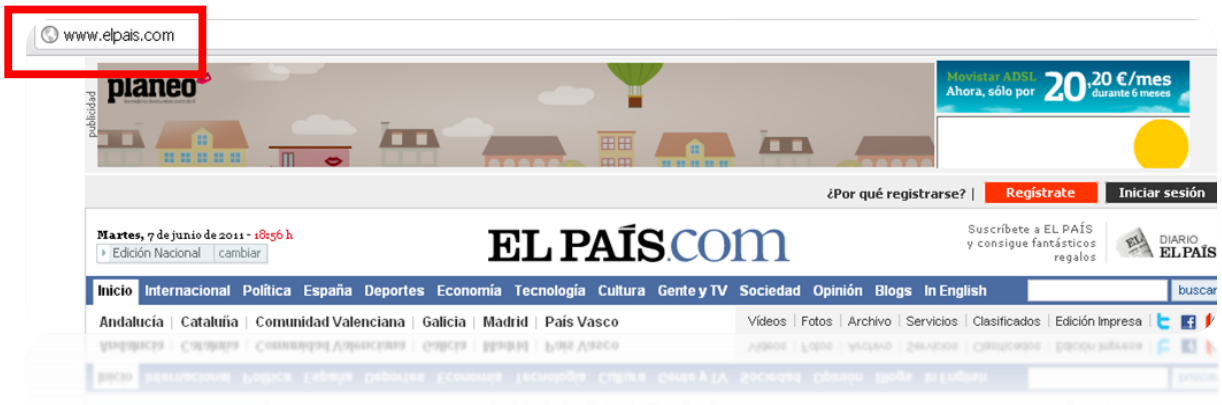

Además, cada una de las páginas que contienen son claras y permanentes.

Contenidos o servicios que ofrece el sitio web

Todos los contenidos que ofrece este espacio web se indican en su home page cuya función es la de escaparate del sitio:

Una primera parte o parte superior dedicada al área de navegación.

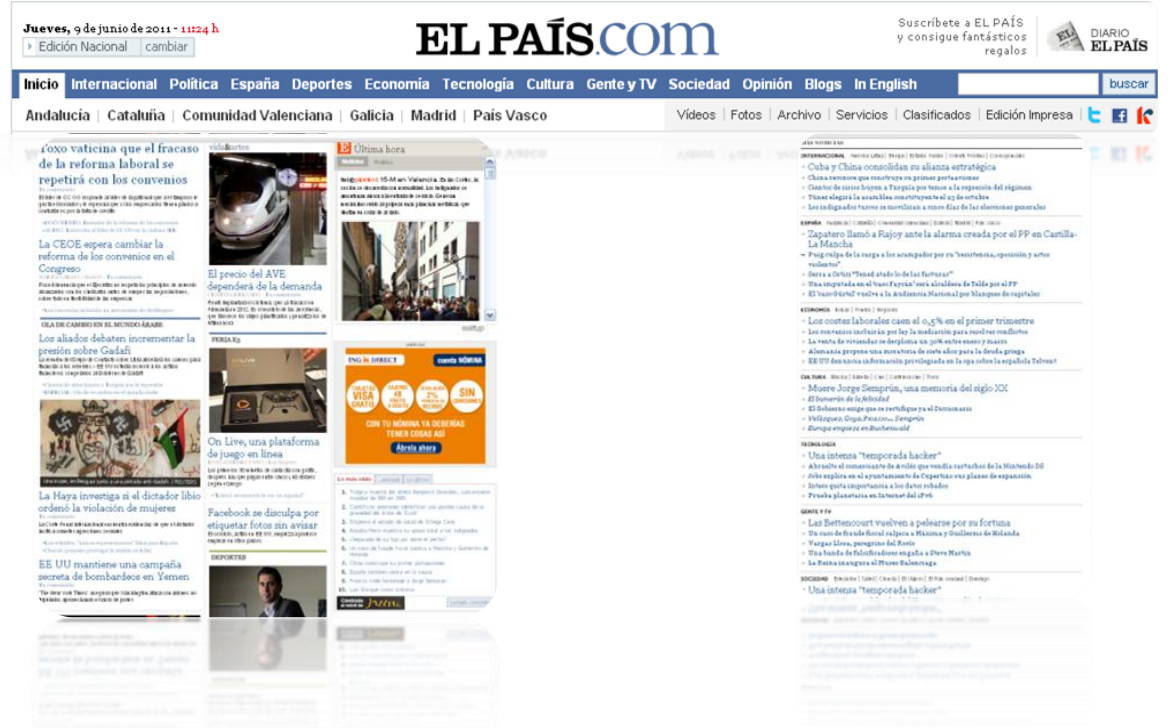

La parte central está dedicada a los contenidos más importantes que ofrece la página; y su parte inferior contiene información dividida en bloques.

Look and feel general

La imagen de este espacio web transmite una seria apariencia debido al uso de sus colores corporativos y la información contenida. Como hemos visto hasta ahora, utiliza colores, como son el blanco, azul y negro, que muestran una imagen formal y profesional relacionada con sus objetivos y contenidos.

Diseño general del sitio web

El sitio web del diario El País mantiene una serie de rasgos y características en cada una de sus páginas web: logotipo, áreas de navegación o estructura son algunas de esas características. 
Reconocimiento del diseño general del sitio web

El diseño general de este sitio web es reconocible al corresponderse con el diseño que presentan el resto de espacios que tienen unos mismos objetivos: la información en general. Esto hace que su navegación destaque por su facilidad.

Actualización del sitio web

Su actualización es constante. Según información de El País, "ELPAIS.com está actualizado permanentemente, las 24 horas del día, los siete días de la semana. Nuestra redacción se encarga de publicar las últimas informaciones en la portada del web, donde se resume lo más relevante de la actualidad. En las secciones de ELPAIS.com también se clasifican temáticamente las últimas noticias en tiempo real". De hecho en la parte superior izquierda de la página web, se indica la última hora a la que la web ha sido actualizada.

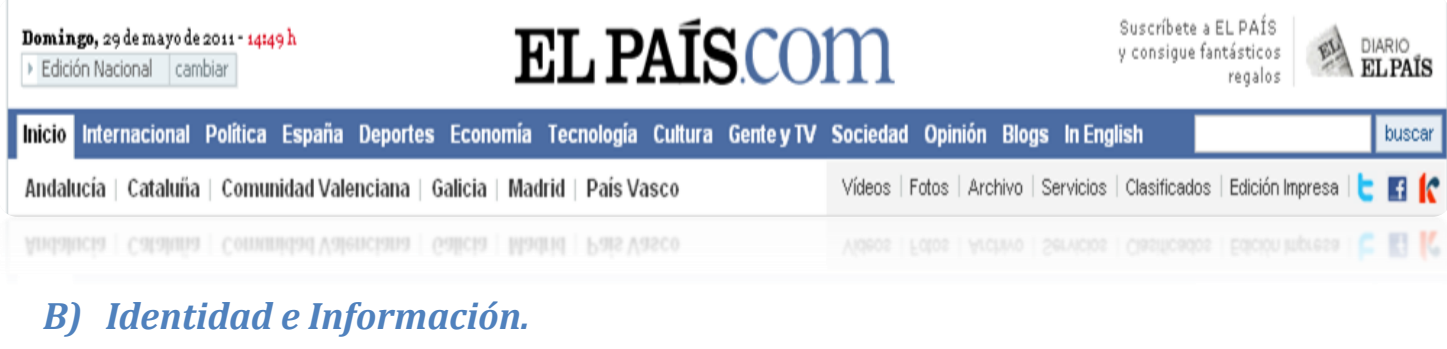

Identidad de la empresa-sitio en todas sus páginas

Todas las páginas que componen este espacio mantienen cada uno de los rasgos corporativos de la empresa.

El Logotipo

El logotipo es identificable al corresponderse con el nombre de su empresa y visible al encontrarse en cada una de las páginas interiores en la parte superior.

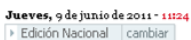

EL PAİSCOM

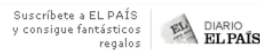

Enlace con información sobre la empresa

Elpaís.com no ofrece algún tipo de enlace con información sobre la empresa; pero, en la parte superior de esta página, encontramos un enlace que nos dirige al grupo de comunicación Prisa, el grupo de comunicación al que pertenece este diario. La web de Prisa indica información
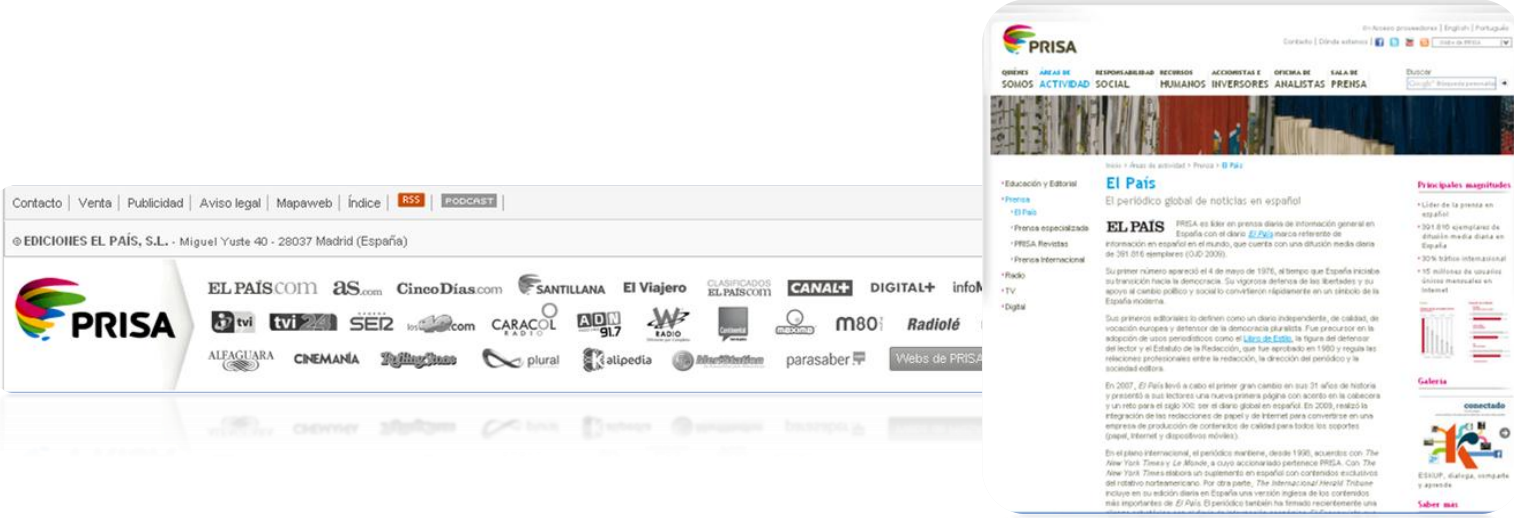
acerca de sus diferentes medios.

Contacto con la empresa

Cabe la posibilidad de establecer contacto con la propia empresa a través de diferentes mecanismos: teléfono, correo electrónico o a formulario que se completa en la propia web. Además, incluye varios apartados dependiendo del receptor al que vaya dirigida la consulta.

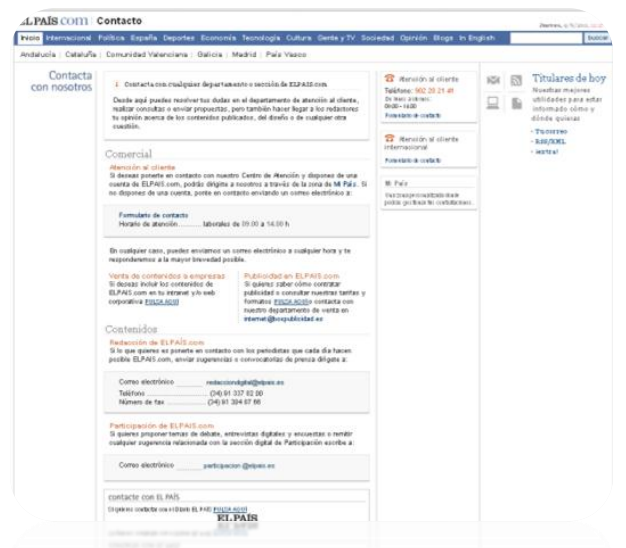

Protección de datos

Este espacio web incluye un apartado en el que se proporciona información sobre la protección de datos de carácter personal de los clientes.

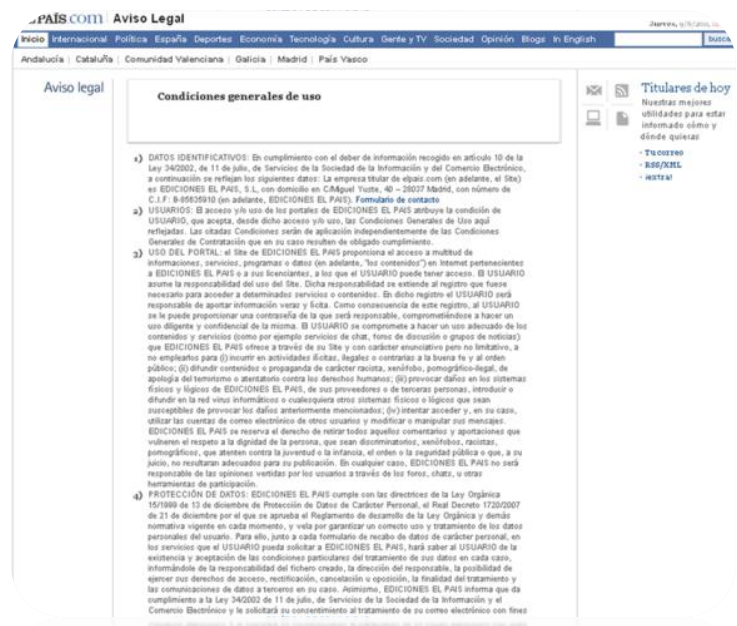

Información sobre los documentos que contiene 
Los textos que contiene la página web indican claramente el nombre de su autor o fuente y la fecha de creación del texto en cuestión.

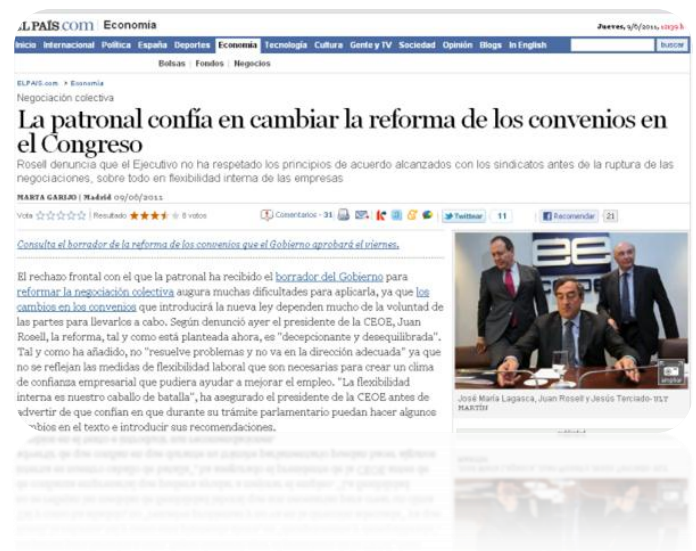

\section{C) Lenguaje y Redacción}

Lenguaje y lengua

La información emplea un lenguaje claro y sencillo al estar dirigida a un amplio público de diferentes edades y diferentes características socio-culturales. Asimismo, se encuentra redactada en lengua castellana al ser un diario de ámbito nacional, pero contiene un apartado en lengua inglesa con la información más relevante redactada en este idioma.

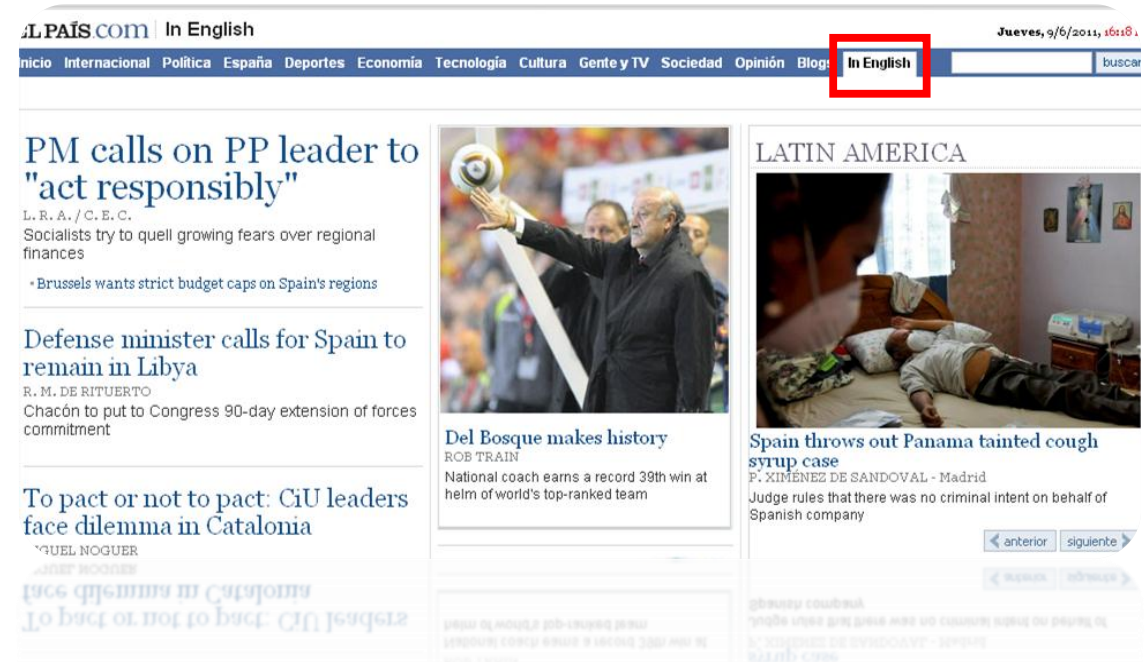

D) Rotulado, Estructura y Navegación 
Rótulos

El sitio web ha elegido un formato tipo estándar para elaborar cada uno de sus rótulos.

ELPAÎ́S COM España

Jueves, $9 / 6 / 2011,1603$ t h

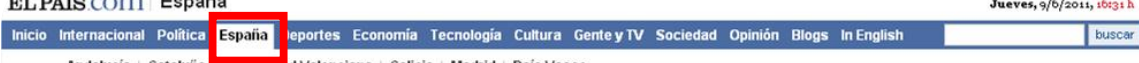

Andalucia | Cataltuía coumunund Valenciana | Galicia | Madrid | Pais Vasco

POLÍTICA nueva seccón en El PAIS s

Zapatero llamó a Rajoy ante la

alarma creada por el PP en Castilla La Mancha

El presidente pidió "prudencia, seriedad y responsabilidad" ante los mercados Salgado lé reiteró ese mensaje el martesy el líder popular le ofrecíó "lealta-

La deuda de la sanidad española se dispara y alcanza los 9.400 millones MARIA R. SAHUQUILLO / Madrid

En tres años elvolumen de facturas pendientes de cobro se ha duplicado. -Andalucía, Comunidad Vienciana y Madrid s

- Los hospitales públicos deben medicamentos de un ańo

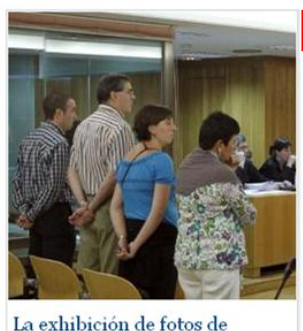

La exhibición de fotos de etarras es terrorismo, según el Supremo
JULIO M. LAZA. La sentencia contradice el criterio de la
Audiencia Nacional
DE LUNES A VIERNES A LAS 8.00

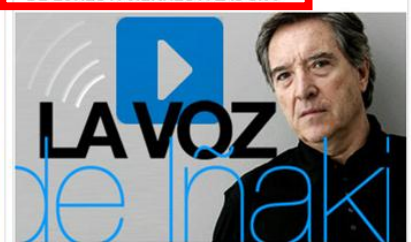

Homenaje a Jorge Semprúm Gabilondo recuerda la figura del intelectual y politico fallecido: "Su figura nos recuerda los essantos twivios en
Europa, y comol logró estabilizarse en torno a la paz" - ¿Y tú que opinas? Comenta el blog · 0 en Facebook 
Sistema de organización

El sitio web ha elegido un sistema de organización lógico estructurado temáticamente y orientado al público.

Título de las páginas

Cada uno de los títulos de las páginas web de este espacio, se corresponden con el contenido que presentan. Además, al utilizar un sistema de etiquetado bastante claro, hace que aumente la findability del sitio web. De manera que, si en un buscador, indicamos "deportes el país", este nos devuelve en su primera página la sección de deportes del diario El País.

Enlaces

Se reconocen a la perfección los enlaces que se encuentran en la página al estar marcados mediante negritas $y$, cuando se trata del enlace que nos dirige hacia otra sección, cambia su color. Además, son nombrados de tal manera que el usuario puede predecir perfectamente el contenido que encontrará antes de hacer clic sobre el enlace.

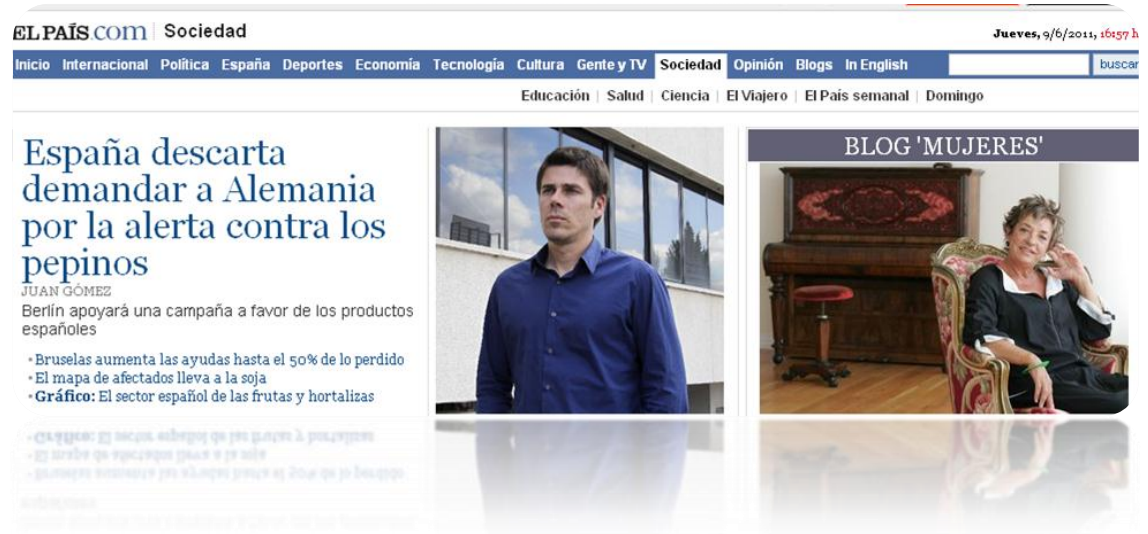

Enlaces rotos

El sitio web de El País no contiene enlaces rotos, es decir, enlaces que no lleven a ningún sitio.

Orientación del usuario

El sistema de navegación de este espacio se encuentra organizado en diferentes secciones. Cuando el usuario entra en una de ellas, el nombre de la sección en cuestión cambia de color (como puede comprobarse en imágenes anteriores), con lo cual, el usuario siempre estará orientado cuando navegue por las páginas de este sitio web. Además, el logotipo de Elpaís.com aparece en cada una de las páginas interiores que, al hacer clic sobre él, nos dirige hacia la home page.

Imágenes enlace 
Las imágenes enlace se reconocen como clicables, pues al situarnos sobre ellas la flecha del ratón se vuelve un indicador mediante el dedo de una mano, y, además, incluyen el atributo

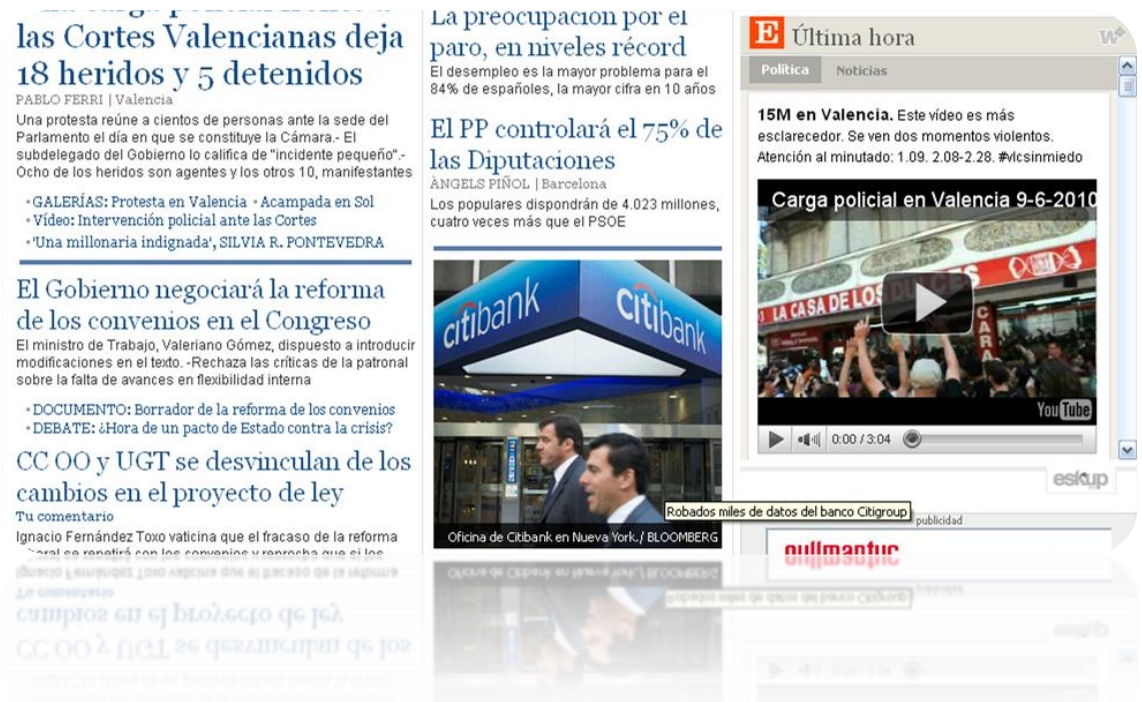

"title" para describir la página de destino. Si nos situamos con el ratón sobre la imagen, podemos observar cómo aparece el atributo "title" que nos describe hacia dónde nos dirige este enlace.

\section{E) Lay-Out de la Página}

Zonas de alta jerarquía

La página inicial se estructura de acuerdo a la relevancia y actualidad. Cuanto más superior sea la zona en que está situada una determinada noticia, más importante y actual será.

Sobrecarga informativa

La página web contiene un total de 13 secciones, lo cual es superable a lo recomendable para evitar la sobrecarga informativa. Sin embargo, y en cuanto al color, puede afirmarse que su uso ha sido controlado al utilizarse simplemente 3 colores, los correspondientes a su corporativismo.

Longitud de página

La página de inicio es demasiado extensa; la barra de desplazamiento ha de moverse demasiado para dirigirnos desde su parte superior hasta su parte inferior.

\section{F) Búsqueda}

Caja de búsqueda

La caja de búsqueda se encuentra fácilmente accesible al situarse en la parte superior derecha del sitio web y en cada una de sus páginas interiores.

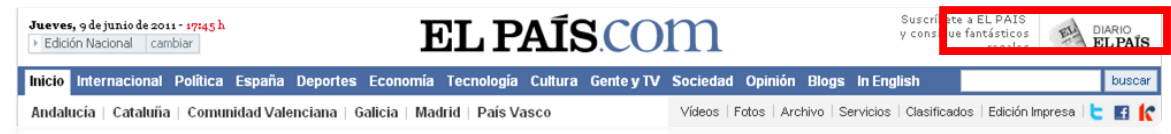


Además, permite realizar una búsqueda avanzada mediante diferentes filtros: fecha, formato, género y sección.

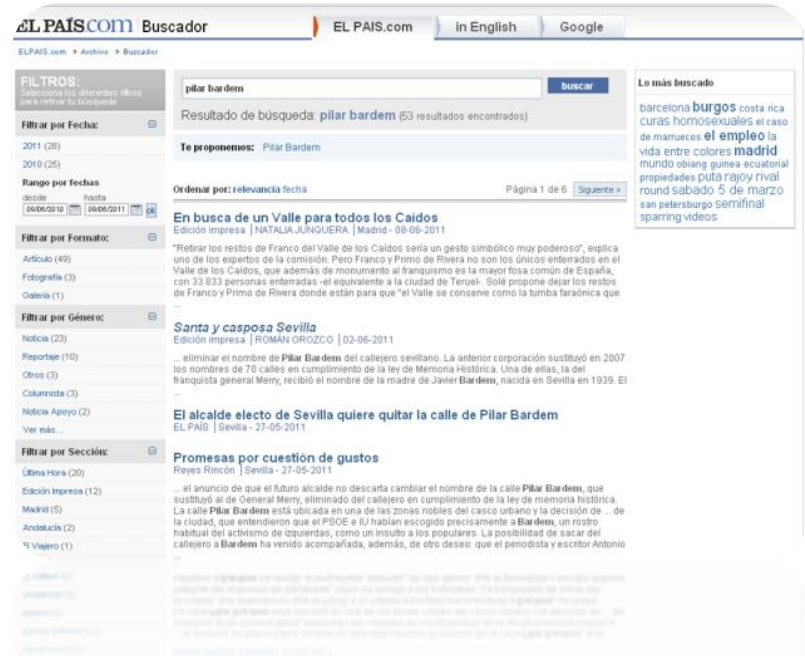

\section{G) Elementos Multimedia}

Fuentes y formatos

La página web www.elpais.com contiene, además de texto, diferentes formatos audiovisuales como son imágenes fijas y en movimiento. Se puede acceder a través de uno de los submenús de navegación.

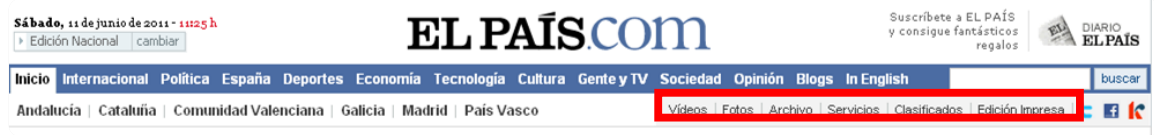

Fotografías

Las imágenes fijas contenidas en este sitio web están bien recortadas, son comprensibles y se ha cuidado su resolución.

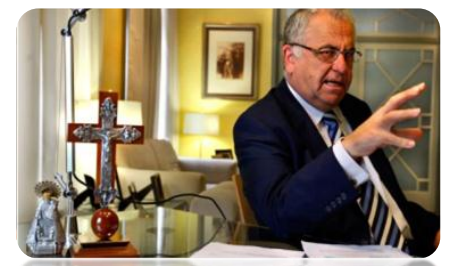

Metáforas visuales

Este sitio web contiene metáforas visuales. Estas son reconocibles y comprensibles por cualquier usuario ya que simbolizan estándares. Además, son acompañadas por un texto que indica el significado de esta. 


\section{H) Accesibilidad}

Fuente

La fuente de este sitio web es de tipo tipográfico estándar y, además, el ancho de línea, alienación y el contraste entre el color de fuente (negra) y fondo (blanco) facilitan la lectura.

Atributos "alt"

Las imágenes de este espacio web, presentan atributos "alt" que describen su contenido. Esto puede comprobarse mediante el acceso al código fuente de la página.

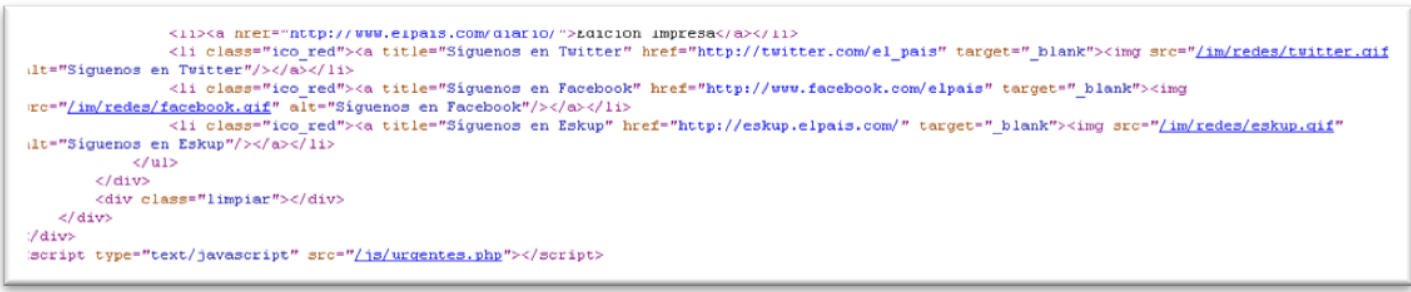

Compatibilidad con diferentes navegadores

La página web puede ser visualizada por los navegadores más importantes: Internet Explorer, FireFox y Google Chrome.

Instalaciones de plugins adicionales

No es necesaria la instalación de plugins adicionales para su visualización. 
EL MUNDO DIGITAL

\section{ELOMUNDO.es}

Su edición impresa aparece en el año 1989 y su fundador es Pedro J. Ramírez. Perteneciente al grupo de comunicación Unidad Editorial.

La dirección de la edición impresa la desempeña Pedro J. Ramírez y la dirección digital Fernando Baeta. Su editor responsable es Unidad Editorial. Cuenta con un total de 2 ediciones: Edición España y Edición América.

\section{A) Información General.}

Objetivos

Este espacio no indica de forma explícita sus objetivos, pero mediante la navegación por la página web puede entenderse que el objetivo de este espacio es la información generalista y constante actualización.

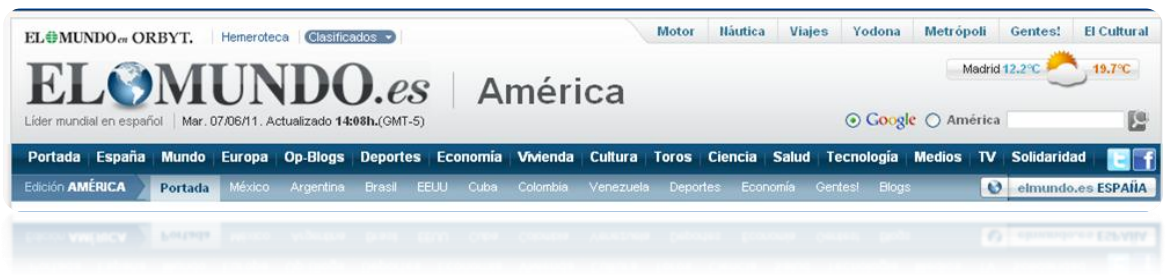

URL

La edición electrónica del diario El Mundo se encuentra en la siguiente URL: www.elmundo.es. Además, cada una de las páginas que contienen son claras y permanentes.

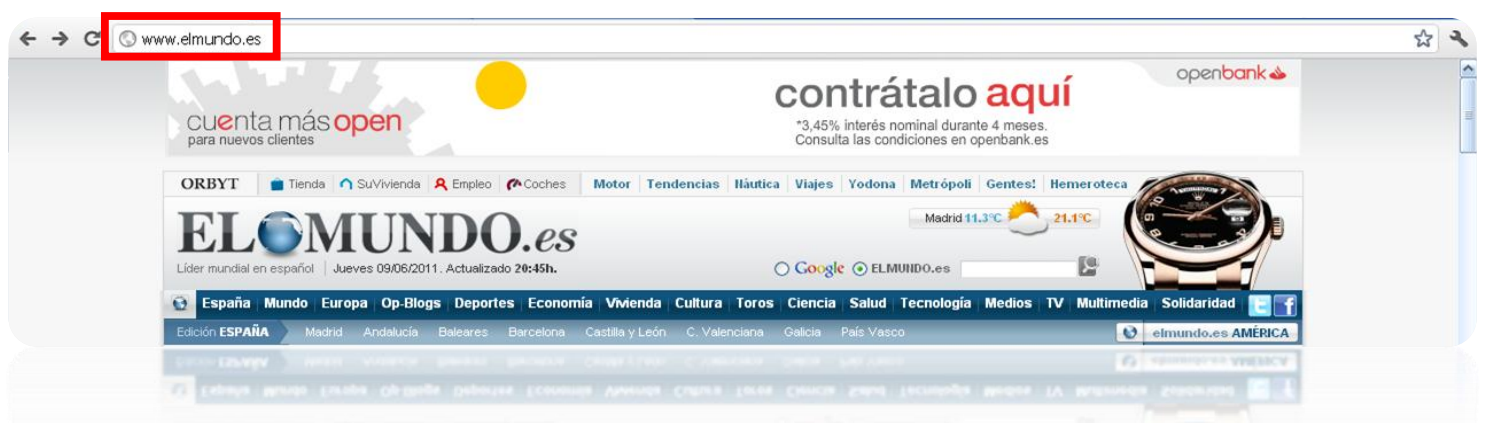

Contenidos o servicios que ofrece el sitio web

Los contenidos y servicios que ofrece este sitio web aparecen indicados en su página principal. 
En su parte superior se indica el área de navegación.

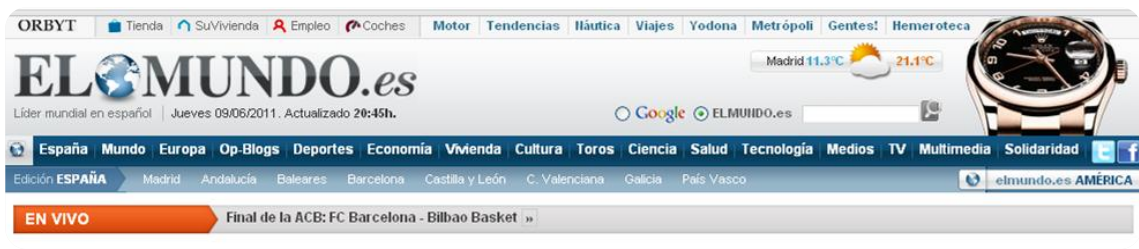

La parte central está dedicada a la información más importante y actual del momento.

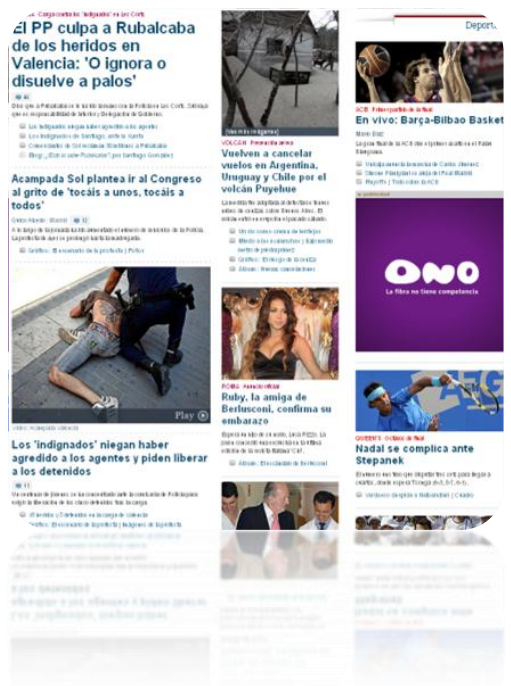

A diferencia del diario El País, la parte inferior de la página principal no contiene una diferenciación de las distintas secciones, sino que contiene secciones especiales.

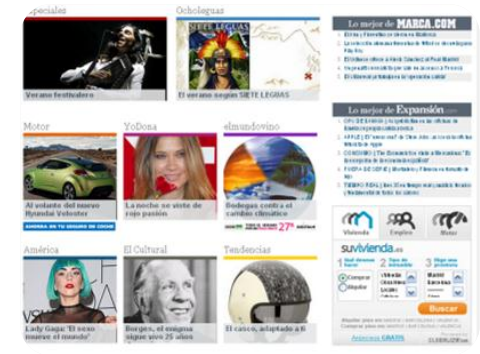

Look and feel general

La apariencia de este espacio web transmite una imagen seria y formal. Esto puede expresarse a través de sus colores corporativos y la información que contiene. Sus colores son básicos y neutros como el azul, el blanco y el negro y el contenido es puramente informacional. 
Diseño general del sitio web

El diseño general del sitio web mantiene rasgos corporativos en cada una de sus páginas interiores. Así, el logotipo aparece en cada una de ellas en su parte superior.

Reconocimiento del diseño general del sitio web

Es reconocible el diseño general de este sitio web al asemejarse con el resto de diarios digitales generalistas que encontramos en la Red.

Actualización del sitio web

Según datos de EI Mundo, "elmundo.es se actualiza las 24 horas del día, para que no te pierdas nada de lo que pasa en el mundo. La información de última hora la podrás encontrar fácilmente en la portada del web, organizada por secciones. Además, hemos preparado en 'La actualidad en 60 segundos' un documento para que en un minuto te enteres de lo más importante que se cuece en todo el mundo". Al igual que en el diario digital El País, el espacio web de El Mundo cuenta con un pequeño apartado en el que indica el último momento de actualización.

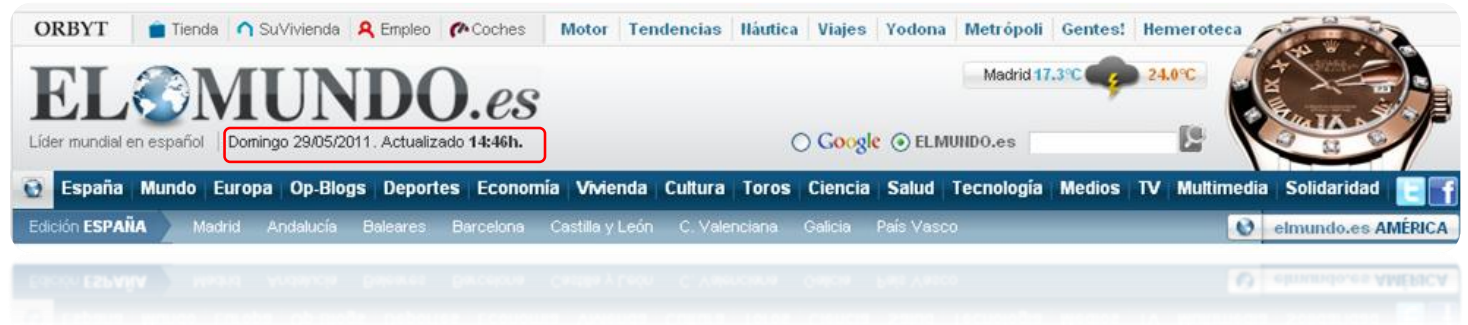

\section{B) Identidad e Información}

Identidad de la empresa-sitio en todas sus páginas

Cada una de las páginas web que contiene este espacio, mantiene su estructura y rasgos corporativos de la empresa.

\section{El Logotipo}

El logotipo es reconocible al corresponderse con el nombre de su empresa. Asimismo, aparece en cada una de las páginas web en la parte superior izquierda de estas.

Enlace con información sobre la empresa

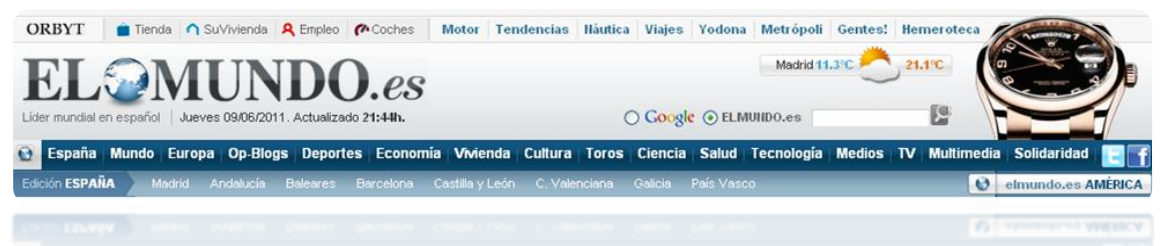

El portal del diario El Mundo contiene abundante información sobre la empresa. Contiene un espacio dedicado al equipo humano de trabajo, "Quiénes Somos", y otro espacio dedicado a información sobre la actividad y funcionamiento de la página web. 

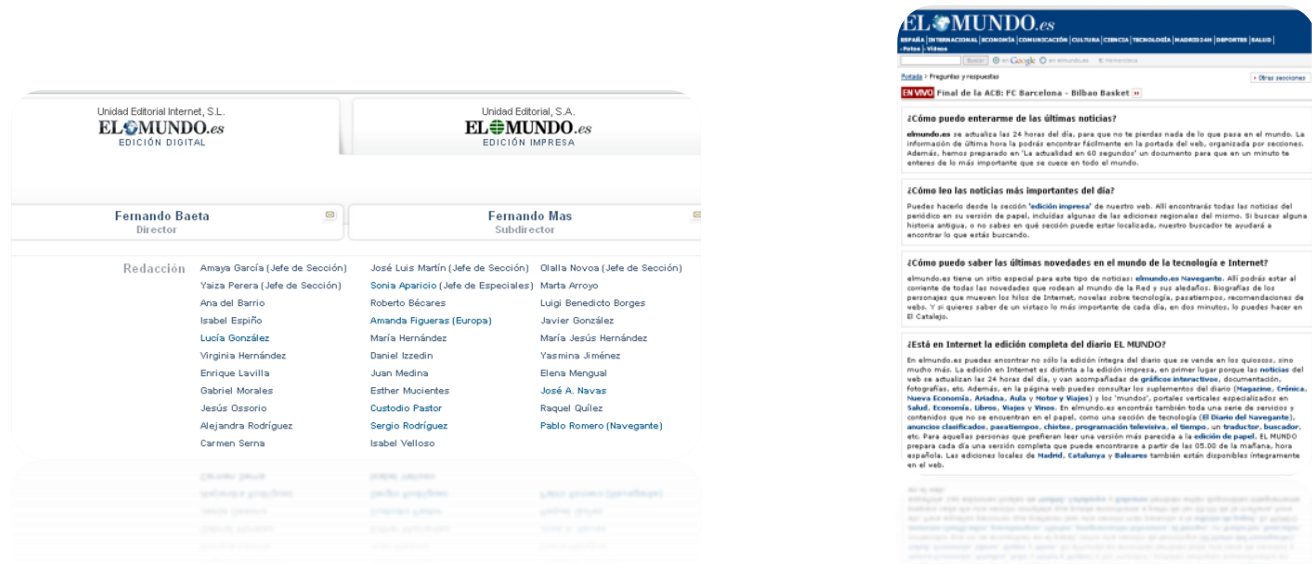

Contacto con la empresa

Este sitio web contiene un espacio dedicado al contacto con la empresa. Establece una diferenciación entre su edición impresa y su edición digital, proporcionando diferentes modos de contactar y diferentes correos electrónicos a los cuales dirigir una consulta.
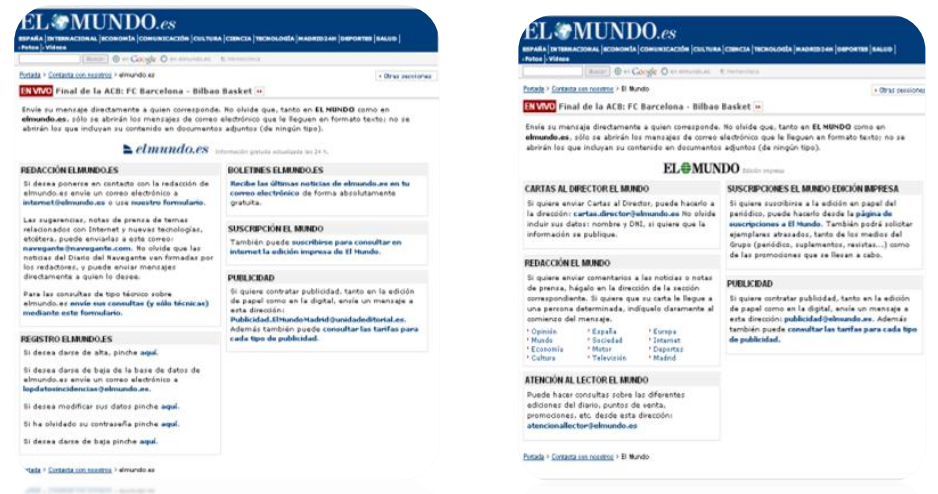

Protección de datos

Elmundo.es contiene dos enlaces que dirigen hacia políticas de protección de datos y derechos de propiedad intelectual. En el primer caso, nos indica cuál es la política de privacidad para aquel usuario que navegue a través de la página web. 
Información sobre los documentos que contiene

Cada uno de los textos que contiene la página web, se identifican nombrando al autor y fecha

de elaboración.
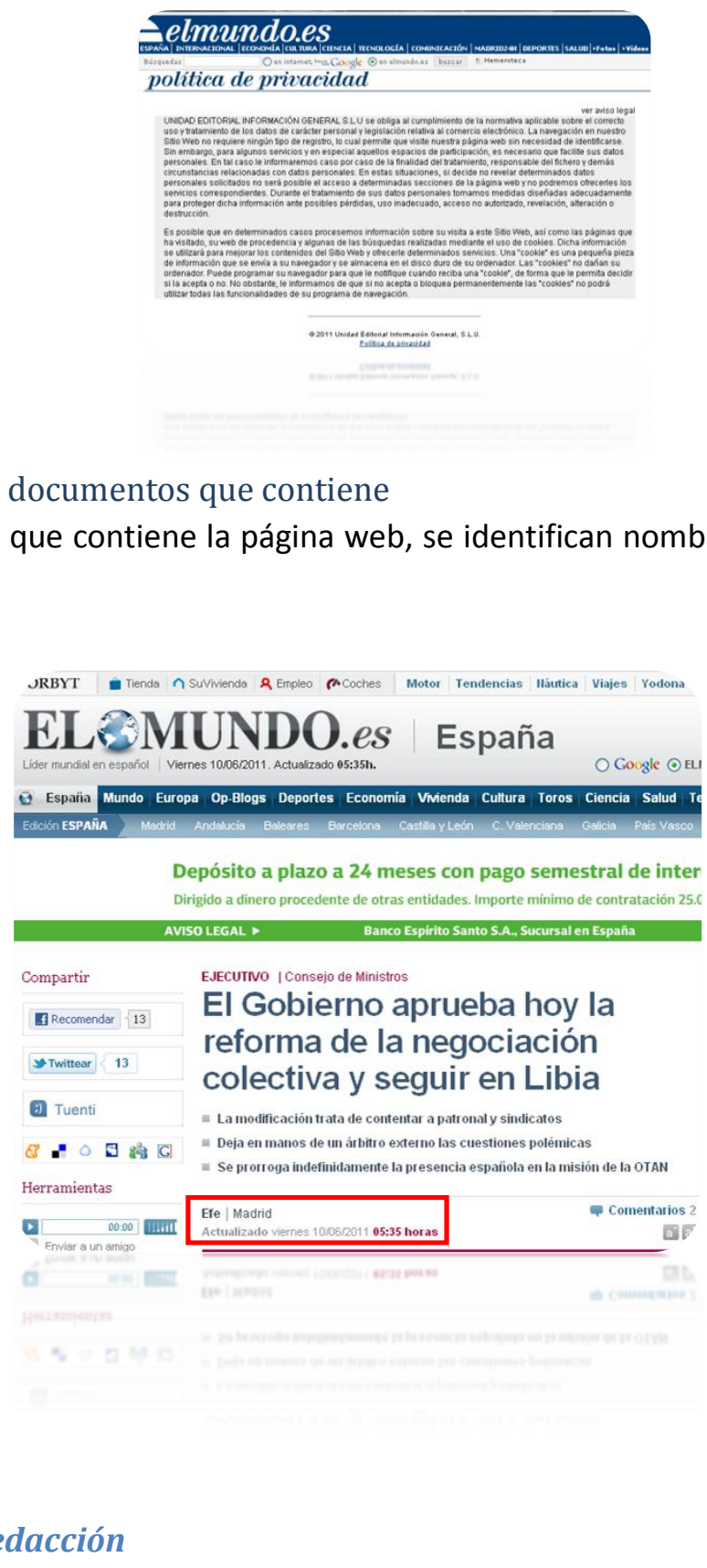

Lenguaje y lengua

Los textos que componen este espacio contienen un lenguaje claro y sencillo puesto que la segmentación de mercado que lee este diario es bastante amplia. La lengua que emplea es la castellana y, a diferencia del diario El País, no contiene ningún espacio dedicado a la redacción de otro idioma.

D) Rotulado

Rótulos 
El tipo de rótulo que ha elegido esta web para titular los diferentes contenidos es de tipo estándar.

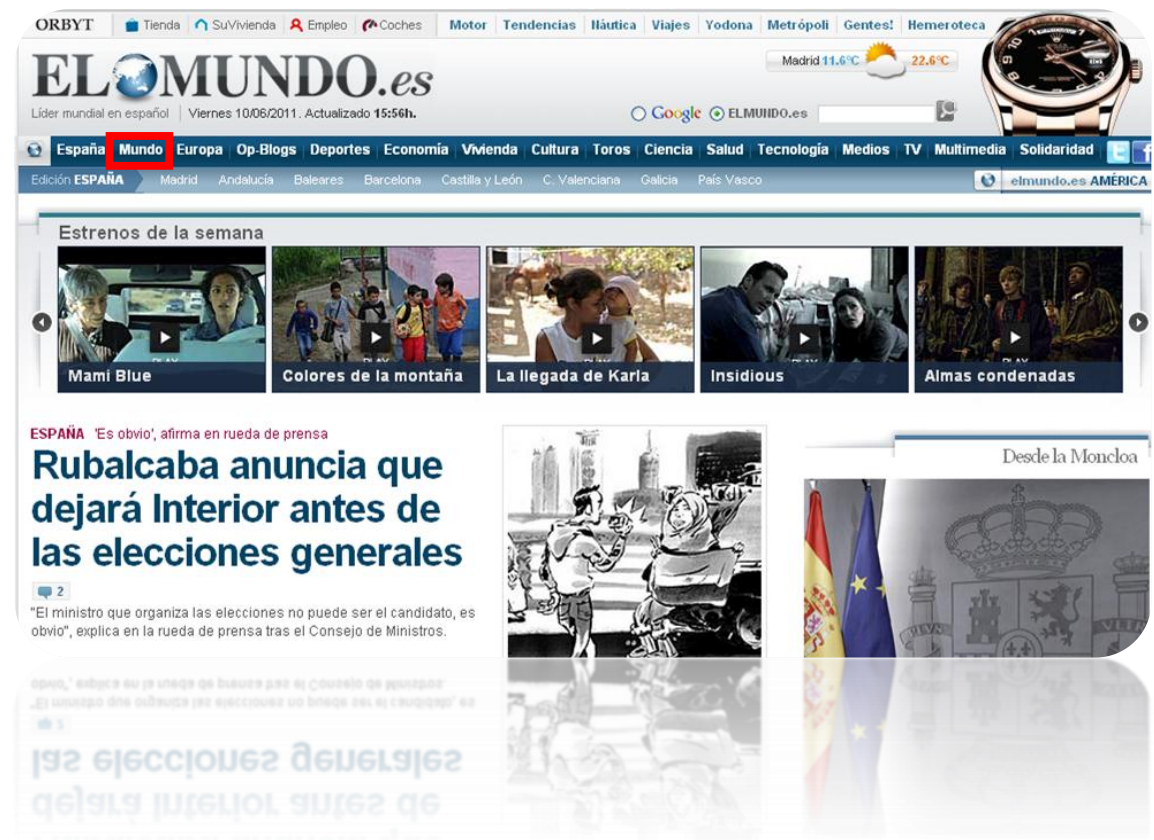

Sistema de organización

El espacio web se estructura de forma lógica y orientada al usuario, además de hacerlo de manera temática (esto puede verse en cada una de sus secciones del área de navegación).

Título de las páginas

El contenido de cada una de las páginas web se corresponde con su titulado, además de haber utilizado un sistema de etiquetado bastante claro, pues al realizar una pregunta sobre una página en cuestión de este espacio en un motor de búsqueda, nos direcciona directamente a esta página.

\section{Enlaces}

Los enlaces que contiene este espacio web se reconocen perfectamente al presentarse en negritas. Además, cuando se trata de enlaces referidos a las diferentes secciones que contiene el espacio, cambia de color. Los enlaces se describen de tal modo que el usuario puede predecir lo que encontrará en ellos tras cliquearlos.

\section{Enlaces rotos}

Elmundo.es no contiene enlaces rotos, es decir, enlaces que no nos dirijan a ninguna página interna.

\section{Orientación del usuario}

Cuando un usuario se encuentra en una determinada página interna, siempre y gracias a la organización de sus secciones va a estar orientado y conocerá dónde se encuentra en el momento. Asimismo, el título de la sección en la que se halla, cambia su color. Otra de las características que hace que el usuario no se pierda al navegar por la página web es la función 
del logotipo situado en la parte superior a la izquierda. Si hacemos clic sobre él, nos devuelve a la página principal.

Imágenes enlace

Las imágenes enlace se reconocen como clicables porque al situarnos sobre ellas, la flecha del ratón se convierte en otro indicador representado por una mano que demuestra que esa imagen es clicable. Las imágenes, además, incluyen atributos "alt" que nos describen hacía dónde nos dirige esta imagen.
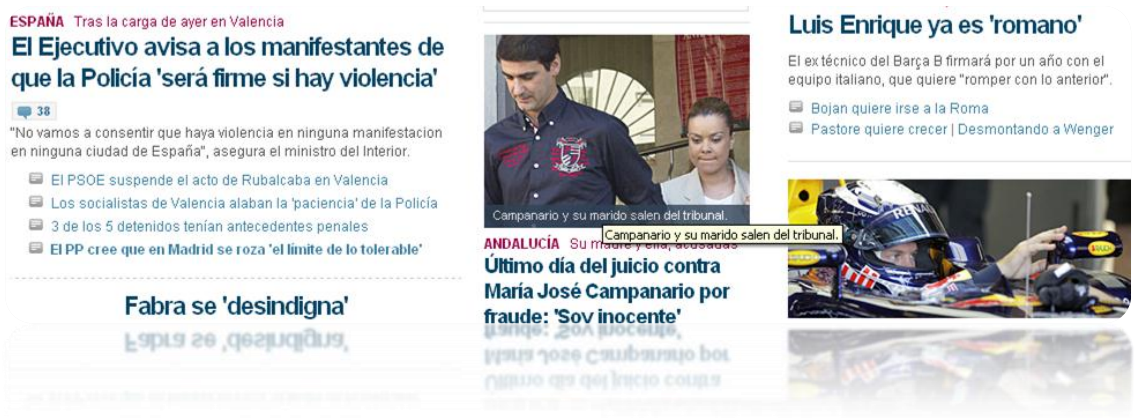

E) Lay-Out de la Página

Zonas de alta jerarquía

La home page se organiza atendiendo a la importancia y actualidad de los textos que se encuentran en ella. La zona superior, por lo tanto, indica que ese texto es de mayor relevancia y actualidad.

\section{Sobrecarga informativa}

La página web contiene un total de 16 secciones, que es superable a lo recomendable para evitar la sobrecarga informativa. En cuanto al color de este espacio, se ha mantenido con colores neutros como son el negro, el blanco y el azul, que corresponden a sus colores corporativos.

\section{Longitud de página}

La home page puede caracterizarse, también, por su extensa longitud, lo cual hace que desplacemos en gran medida la barra de desplazamiento para dirigirnos desde la zona superior a la inferior.

\section{F) Búsqueda}

\section{Caja de búsqueda}

Al igual que la gran mayoría de sitios web, la caja de búsqueda se halla en la parte superior derecha de cada una de sus páginas. Cabe la posibilidad de realizar la búsqueda en el buscador Google o en el propio diario.

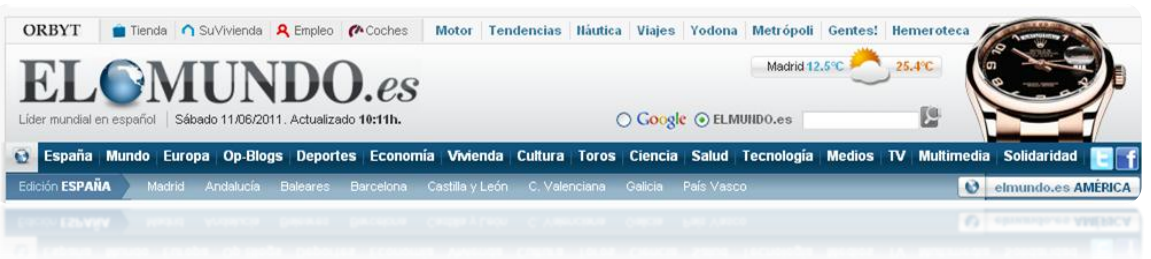


Asimismo, permite realizar una búsqueda avanzada mediante diferentes filtros: fecha, sección y suplementos. Pero dispone de un cuarto filtro en el que la búsqueda puede realizarse por tipo de formato: Todo, Noticias, América, Blogs, Fotos y Vídeos.

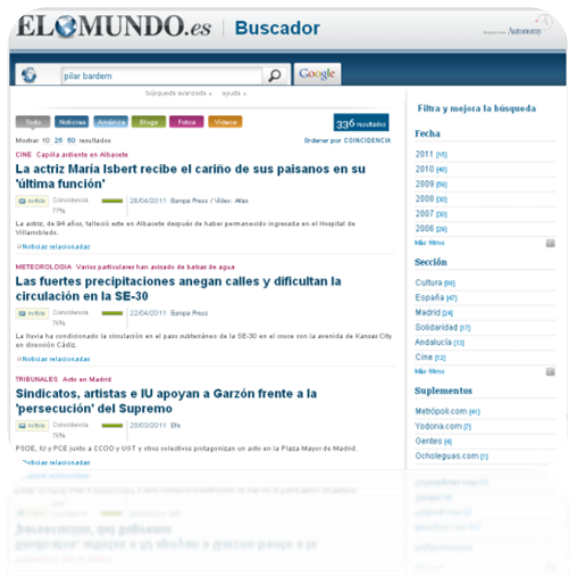

G) Elementos Multimedia

Fuentes y formatos

Este espacio web dispone tanto de texto como de imágenes fijas y en movimiento que las podemos encontrar en uno de los apartados del área de navegación "multimedia". 


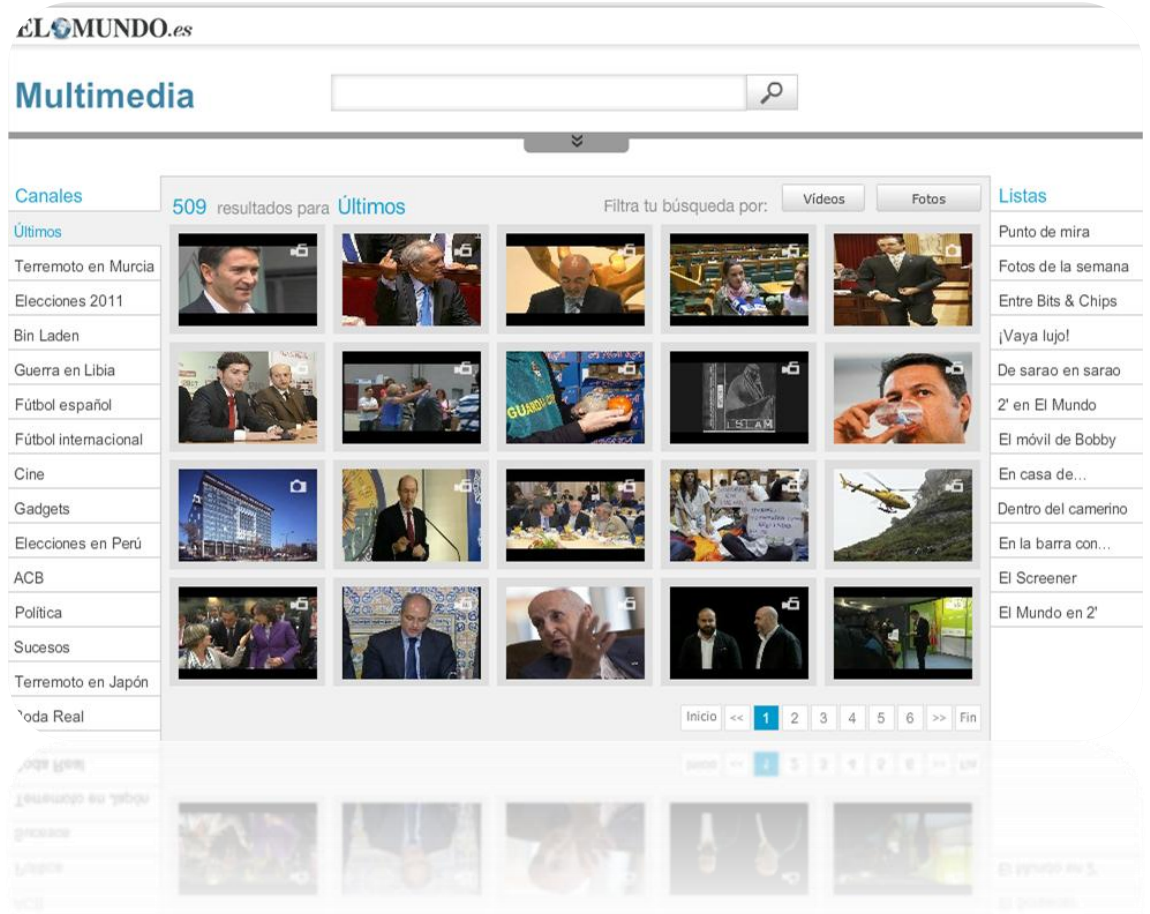

Fotografías

Este espacio web contiene fotografías que han cuidado tanto su resolución como su recorte.

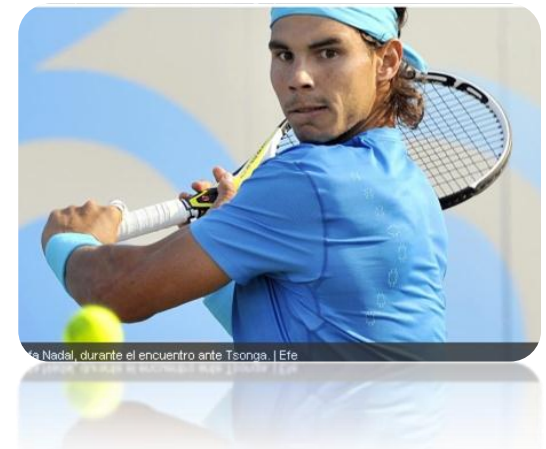

Metáforas visuales

Las metáforas visuales en esta web son reconocibles y comprensibles por la gran mayoría de usuarios al representar estándares. Algunas de ellas, están acompañadas de un texto para facilitar su comprensión, pero otras no lo tienen de forma explícita, sino que podemos situarnos sobre ella y una pequeña indicación nos dice lo que significa tal metáfora. 


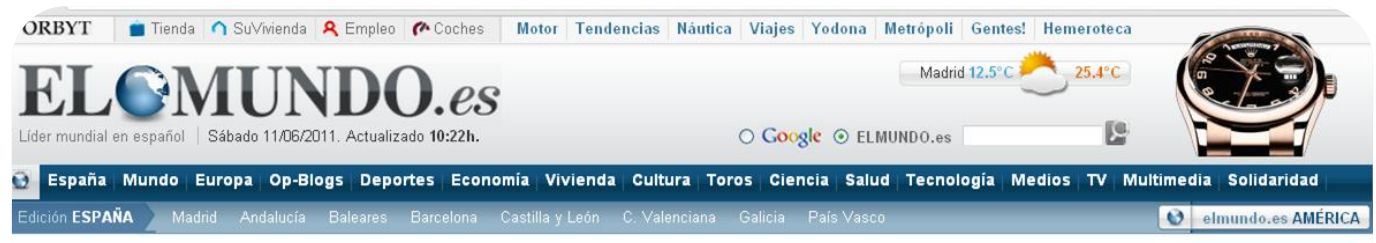

EE ElECCTONES país vasco En un pleno sin sorpresas

Bildu logra la Alcaldía de San Sebastián tras 20 años en manos socialistas

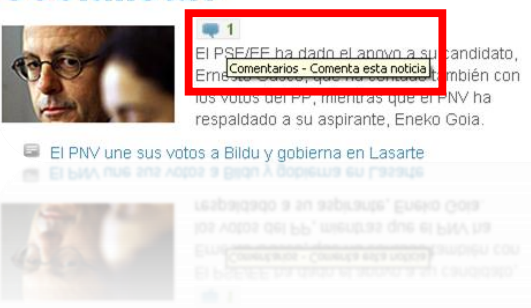

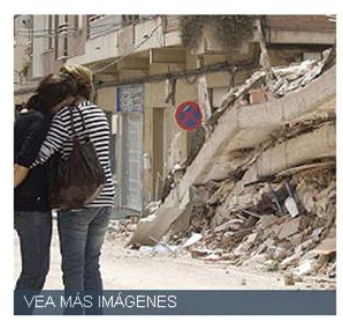

LORCA Un mes del seismo Los daños que no se ven roe q9uor dne no ze ^eu

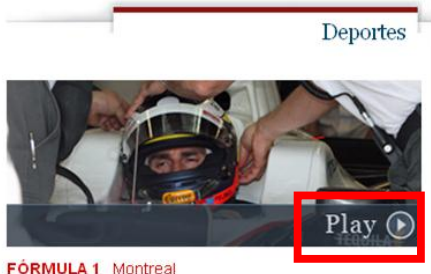

RMULA 1 Montrea

De la Rosa, sorpresa en Canadá

\section{H) Accesibilidad}

Fuente

Elmundo.es contiene una fuente de tipo tipográfico estándar. El ancho de la línea, alineación y el contraste entre el color de la fuente (negro) y el fondo (blanco) facilitan la legibilidad.

Atributos "alt"

Este espacio web contiene atributos "alt" que describen su contenido. Esto lo comprobamos accediendo al código fuente de la página.

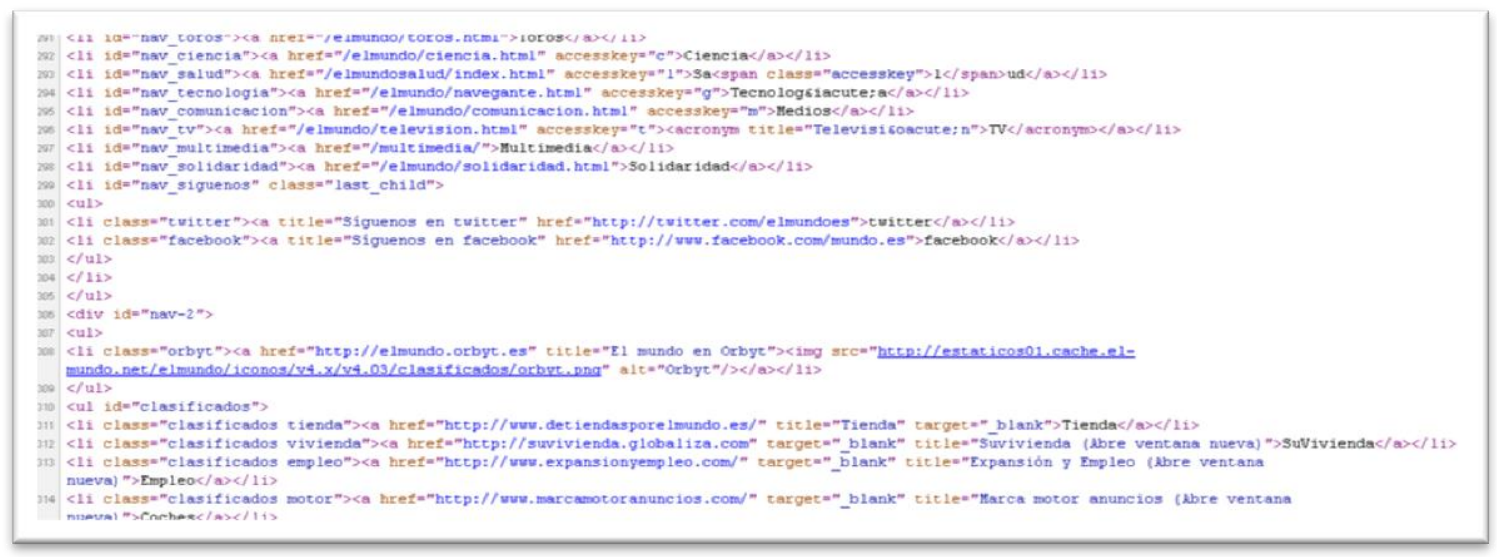

Compatibilidad con diferentes navegadores

No se encuentra problema alguno para el acceso de la página web www.elmundo.es con los tres navegadores más conocidos: Internet Explorer, Firefox y Google Chrome.

Instalaciones de plugins adicionales

No se necesitan plugins adicionales para navegar a través de la página web. 


\section{REFERENCIAS BIBLIOGRÁFICAS Y WEBGRAFÍA}

\section{Bibliografía}

Hassan Montero, Yusef; Martín Fernández, Francisco Jesús (2003). Guía de evaluación heurística de sitios web. http://www.nosolousabilidad.com/articulos/heuristica.htm [Consultado: 01-10-2011]

\section{Webgrafía}

http://www.elmundo.es

Diario El Mundo (Consultado: 1-10-2011)

http://www.elpais.com

Diario El País (Consultado: 1-10-2011)

\section{http://www.aimc.es//-Datos-EGM-Resumen-General-.html}

Estudio General de Medios (Consultado: 1-10-2011)

http://www.ojd.es/

Oficina de Justificación de la Difusión (Consultado: 1-10-2011)

\section{Reconocimiento}

Este trabajo fue financiado por la Consejería de Educación, Ciencia y Tecnología de la Junta de Extremadura junto con el Fondo Social Europeo como ayuda a las labores de investigación del grupo GR10019. 